\title{
Integrated Framework for Reverse Logistics
}

\author{
Heng-Li Yang and Chen-Shu Wang \\ Department of MIS, National Cheng-Chi University, \\ 64, Sec. 2, Chihnan Rd., Mucha Dist, Taipei 116, Taiwan \\ \{yanh,93356506\}@nccu.edu.tw
}

\begin{abstract}
Although reverse logistics has been disregarded for many years, pressures from both environmental awareness and business sustainability have risen. Reverse logistical activities include return, repair and recycle products. Traditionally, since the information transparency of the entire supply chain is restricted, business is difficult to predict, and prepare for these reverse activities. This study presents an agent-based framework to increase the degree of information transparency. The cooperation between sensor and disposal agents helps predict reverse activities, avoid return, speed up repair and prepare for recycling behaviors.
\end{abstract}

Keywords: Reverse Logistics, information transparency, agent-based system

\section{Introduction}

A complete supply chain concept typically includes forward and reverse logistics $[16,17]$. However, reverse logistics has been much less examined than forward logistics. Reverse logistics has recently emerged as crucial issues in both practices and academic studies [13,15,17]. Reverse logistics encompasses planning, implementing and controlling the efficient and cost-effective flow of raw materials, in-process inventory, finished goods and related information from the point of consumption to the point of origin to recapture value or dispose properly [16]. In the European Union, the Waste Electrical and Electronic Equipment (WEEE) directive, this came into force in August 2005, and the Restriction of Hazardous Substances (RoHS) directive, which came into force in 2006; requires companies to take responsibility for product that they sell throughout the product entire lifecycle [8]. Reverse logistics has become imperative for business [4]. Many previous studies have attempted to formulate mathematical models of reverse logistics. Among these studies, Min et al. presented a genetic algorithm model to deploy centralized return centers [12]. Klausner and Hendrickson explored the relationship between product return ratio and reverse logistics strategy [9]. Kulshreshtha and Sarangi examined the link between recycling and price discrimination [10]. Although these optimization models provide partial reverse logistic solutions, they include many assumptions that would not hold in reality. Since reverse logistic activities are too uncertain to formulize [7], the information about them should ideally be combined. Additionally, some studies have investigated this issue from the perspective of the entire supply 


\section{Heng-Li Yang and Chen-Shu Wang}

chain. For instance, Beamon extended the forward supply chain, and proposed the green supply chain concept [2]. Tibben-Lembake and Rogers discussed the distinction between forward and reverse logistics in multiple dimensions [17]. Mollenkopf and Closs discussed the hidden value of reverse logistics from the entire supply chain [13]. Richey et al. surveyed reverse logistics programs, and claimed that information is a critical factor [15].

Companies are increasingly utilizing reverse logistics as a business strategy [9]. For instance, loose return policies might give customers the impression of high product quality [16]. Additionally, a business may earn goodwill from socially or environment responsible behavior [4,13]. However, these reverse logistics strategies might lead to a large amount of returned and recycled merchandise. Businesses require additional information to resolve this vicious circle. Otherwise, the opaque information might invoke a huge bullwhip effect. As business obtains more information, they can predict and prepare, or even prevent bad effects in reverse activities. If the returned products are fashion merchandise, such as $3 \mathrm{C}$ electronic product or seasonal clothes, then the product remaining value might fall when they are sent back by the consumer to the producer site [8]. Therefore, if sufficient information is available to enable businesses to predict returns early, then business could properly prepare and reduce process time to maintain their remaining values.

Additionally, due to the enforcement of WEEE or RoHS in European Union, manufacturers would become concerned with the recycle ratio at any time. This study considers these reverse logistic activities more actively. An agent-based model is presented to increase information transparency degree (ITD) of the entire supply chain management (SCM). A supply chain with a high ITD serves as an early warning system, and works very efficiently. A High ITD enhances information sharing within an entire supply chain management (SCM).

\section{Problem Descriptions}

Previous studies [2,3,6,11,12,13,18] have categorized reverse logistic activities into three groups, as shown in Table 1, namely return, repair and recycle. In the process of forward logistics, suppliers provide raw material to manufacturers, who make products, which are then sent to customers, generally through distributors. Conversely, a customer might send a product back for return, repair or recycling. Additionally, manufacturers and suppliers also need to deal with defective or nonworking products. Recycling collectors need to dispose of these recycled products properly, and transfer reusable materials back to the supplier and manufacturer. This process is known as reverse logistics. These reverse activities have the following problems. (1) If a customer returns product to a distributor, then the distributor might stock returned products to a particular level, then send them back to manufacturer. However, this practice adversely affects the manufacturer, who has less time to process the returned products, thus the lowering their remaining value. (2) Recycling laws, such as WEEE and RoHS in the European Union, increase the importance of recycling activities. Businesses need to monitor recycle ratios, and raise them to 
comply with recycling laws. (3) Finally, in the repair aspect, repairing processing time should be reduced to maintain the image of a business.

Table 1. The definition of reverse logistic activities

\begin{tabular}{|c|c|c|}
\hline Activity & Definition & Result \\
\hline Return & $\begin{array}{l}\text { Consumers return the products } \\
\text { bought within certain period of time } \\
\text { for any reason (rational or } \\
\text { irrational). }\end{array}$ & $\begin{array}{l}\text { Depending on policies, customer } \\
\text { may receive another identical } \\
\text { new product, an equivalent } \\
\text { product exchange or full money } \\
\text { back. }\end{array}$ \\
\hline Repair & $\begin{array}{l}\text { Consumers send broken product to } \\
\text { repair center (or original producer). }\end{array}$ & $\begin{array}{l}\text { Customer generally would } \\
\text { receive workable product back. }\end{array}$ \\
\hline Recycle & \begin{tabular}{lcc} 
Consumers & send & \multicolumn{2}{c}{ unvalued or } \\
unwanted product & to recycling \\
collectors. & &
\end{tabular} & $\begin{array}{l}\text { Customers might or might not } \\
\text { receive rewards. }\end{array}$ \\
\hline
\end{tabular}

All these problems are customer-centric and difficult to predict. However, if the ITD of the entire supply chain could be improved, then the prediction accuracy could be enhanced to enable the upstream and downstream enterprises of supply chain to be prepared early.

\section{Proposed Framework}

This study assumes symbiosis in the entire supply chain system. The supply chain's participants are assumed to share three databases, namely customer, product and transaction. The access permissions are as follows. (1) In the customer DB, the distributor can insert and update and all other participants can only query. (2) In the product DB, the manufacturer can insert and update and all other participants can only query. (3) In the transaction $\mathrm{DB}$, the distributor can insert and update; manufacturer can update, and all other participants can only query. The shared data are updated regularly. This symbiosis assumption is consistent with the concept of strategic partners, in which innovative enterprises share sales data, customer buying patterns and future plans with their partners [14].

Since most reverse activities are triggered by customers, and are hard to predict accurately by conventional analytic approaches, heuristics and AI techniques might help [14]. In the forward supply chain, Piramuthu [5] developed an agent-based framework to automate supply chain configuration, and to improve the performance of the supply chain with dynamic configuration. However, to our knowledge, no study has applied agents to reverse activities. This study presents an agent-based approach. As illustrated in Figure 1, two agents, the sensor agent and the disposal agent, are integrated within the proposed framework. Since an agent could autonomously monitor the changing environment and react automatically to complete a goal, they might helpfully manage this customer-centric problem. 


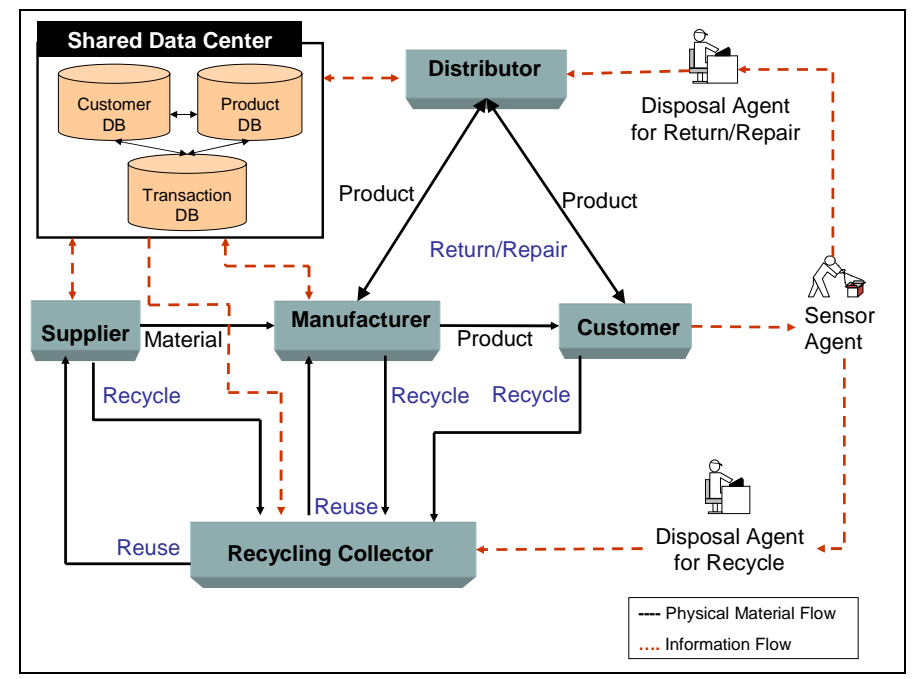

Fig. 1. The proposed agent-based framework

\subsection{The Sensor Agent}

The sensor agent autonomously monitors the recent data, and transmits warning signals to the disposal agent at appropriate times. Additionally, it performs marketing surveys if required. Since product returns might result in serious supply chain problems, return data should be monitored at least weekly. Conversely, since monitoring repair data is likely to be less urgent than monitoring return data, a monthly monitoring period might be sufficient. The possible product recycle time could be estimated from the product life cycle. Therefore, this study recommends enabling active database triggers in customer profile data to provide notice signals. The monitoring should follow rules to detect possible reverse activities. Table 2 lists some such rules.

These rules come from heuristics and data mining results. The sensor agent should periodically perform data mining on the historical data or data warehouse. Some data mining techniques (e.g., those in Table 3) could be considered. The cluster analysis considers some transaction level attributes, e.g., recency, frequency and monetary (RFM) attributes, to cluster customer and discover the reverse activity patterns of customer demographic information. Additionally, in the product dimension, product characteristics could be adopted to cluster products rather than original product types. Furthermore, since some patterns might be cross clusters, the association analysis would take at least two cluster results from cluster analysis as inputs to discover the reverse patterns between these two inputs. For instance, some clusters of customers, who bought products, might be found to have high return ratios. These discovered patterns would be reviewed by experts, and then fed into the rule base of the sensor agent. Therefore, the sensor agent would have a learning capability to improve its own monitoring correctness. 
Table 2. Some rules for detecting reverse activities

\begin{tabular}{|c|c|c|c|c|}
\hline Dimensions & Attributes & $\begin{array}{c}\text { Return } \\
\text { Ratio }\end{array}$ & $\begin{array}{c}\text { Repair } \\
\text { Ratio }\end{array}$ & $\begin{array}{c}\text { Recycle } \\
\text { Ratio }\end{array}$ \\
\hline \multirow[t]{2}{*}{ Customer } & $\begin{array}{l}\text { (recency, frequency, } \\
\text { monetary) }=(\mathrm{H}, \mathrm{H}, \mathrm{M})\end{array}$ & $\mathrm{H}$ & - & $\bar{M}$ \\
\hline & $\begin{array}{l}\text { Gender= Female and } \\
\text { Education= High }\end{array}$ & $\mathrm{H}$ & M & - \\
\hline \multirow[t]{3}{*}{ Product } & Size $=$ Huge & $\mathrm{L}$ & - & $\mathrm{H}$ \\
\hline & Price $=$ High & $\mathrm{H}$ & - & - \\
\hline & Hard to Operating & - & $\mathrm{H}$ & - \\
\hline \multirow{3}{*}{$\begin{array}{l}\text { Customer and } \\
\text { Product }\end{array}$} & Customer_Location= & - & $\mathrm{H}$ & - \\
\hline & Moist and Product $=3 \mathrm{C}$ & & & \\
\hline & Electric Equipments & & & \\
\hline \multirow{2}{*}{$\begin{array}{l}\text { Customer and } \\
\text { Marketing Strategic }\end{array}$} & Customer_Income=Low & $\mathrm{L}$ & - & - \\
\hline & $\begin{array}{l}\text { and Market_Strategy= } \\
\text { "Buy } 1 \text { get } 1 \text { free" }\end{array}$ & & & \\
\hline \multirow{3}{*}{$\begin{array}{l}\text { Product and } \\
\text { Marketing Strategic }\end{array}$} & Product_Size $=$ Small and & $\mathrm{H}$ & - & $\mathrm{L}$ \\
\hline & Market_Strategy= & & & \\
\hline & "Double Credit" & & & \\
\hline
\end{tabular}

Table 3. Examples of data mining of sensor agent

\begin{tabular}{|c|}
\hline Cluster Analysis \\
\hline $\begin{array}{l}\text { Adopting transaction level attributes (e.g., Recency, Frequency, Monetary) to } \\
\text { segment the customers. Then, observing demographic level (e.g., gender, } \\
\text { education, income, location) attributes to discover reverse activity patterns of } \\
\text { customer clusters. }\end{array}$ \\
\hline $\begin{array}{l}\text { Adopting product properties (e.g., size, price, operation) to cluster product to } \\
\text { discover reverse patterns of product properties. }\end{array}$ \\
\hline Association Analysis \\
\hline Finding reverse activity patterns between customer and product clusters. \\
\hline $\begin{array}{l}\text { Identifying reverse activity patterns between customer clusters and marketing } \\
\text { strategies. }\end{array}$ \\
\hline $\begin{array}{l}\text { Detecting reverse activity patterns between product clusters and marketing } \\
\text { strategies. }\end{array}$ \\
\hline $\begin{array}{l}\text { Discovering reverse activity patterns among customer clusters, product clusters and } \\
\text { marketing strategies. }\end{array}$ \\
\hline
\end{tabular}

\subsection{The Disposal Agent}

After receiving signals from the sensor agent, the disposal agent recommends treatments by case-based reasoning (CBR) [1], and reference supplementary rules if necessary. The case base stores successful cases from previous experience. The rule base includes some supplementary heuristics from domain experts. 


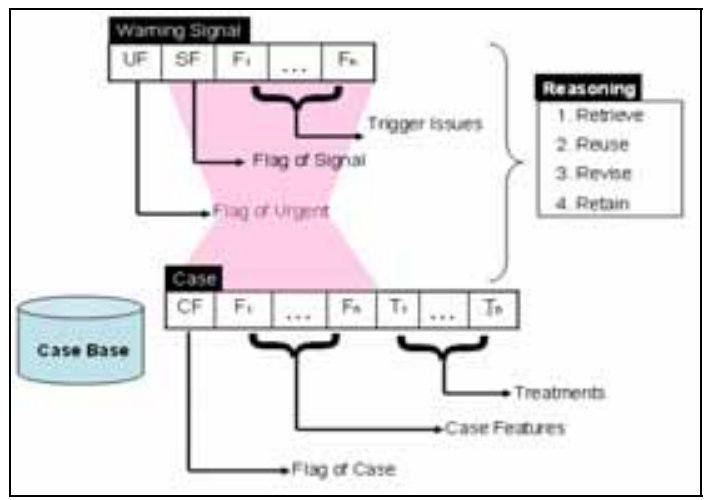

Fig. 2. The case-based reasoning of disposal agent

While (Warning Signal)

$\{$ Reasoning by cases and supplementary rules Switch (UF)

Case: Moderate

1. Suggests some particular treatments

2. Disposal agent performs these treatments automatically

Case: Influential

1. Suggests particular treatments to decision maker for preventing return and enhancing recycling ratio

2. Decision-maker refers these treatments and may revise.

\section{Case: Serious}

1. Suggests treatments to decision-maker.

2. Schedule business processes to prepare for possible reverse activities.

End Switch;

Evaluate performance of suggestion;

If the event performance is good, then retain to Case base

Fig. 3. The disposal agent suggestion

As revealed in Figure 2, a warning signal consists of three parts \{urgent degree (UF), signal flag (SF), trigger features\}. SF could be "return", "recycle”, or "repair". UF indicates degrees of impact. In Figure 3, depending on the different UF, the system would have different actions. It compares $\{\mathrm{SF}$, trigger features\} to those $\{\mathrm{CF}$, case features\} of cases in case base, and retrieve the treatments of the fittest case to decision maker. It might refer to supplementary rules for detailed suggestions or other suggestions (if no suitable case could be found). Then, disposal agent might perform treatments automatically or suggest to decision-makers. It would cooperate with other systems, e.g., programs of scheduling, inventory management or quality checking. If 
the response of this problem solving is good, then the experiences may be annotated by human experts, and then retained in the case base as further references. Therefore, the disposal agent could have learning capability to improve its performance next time.

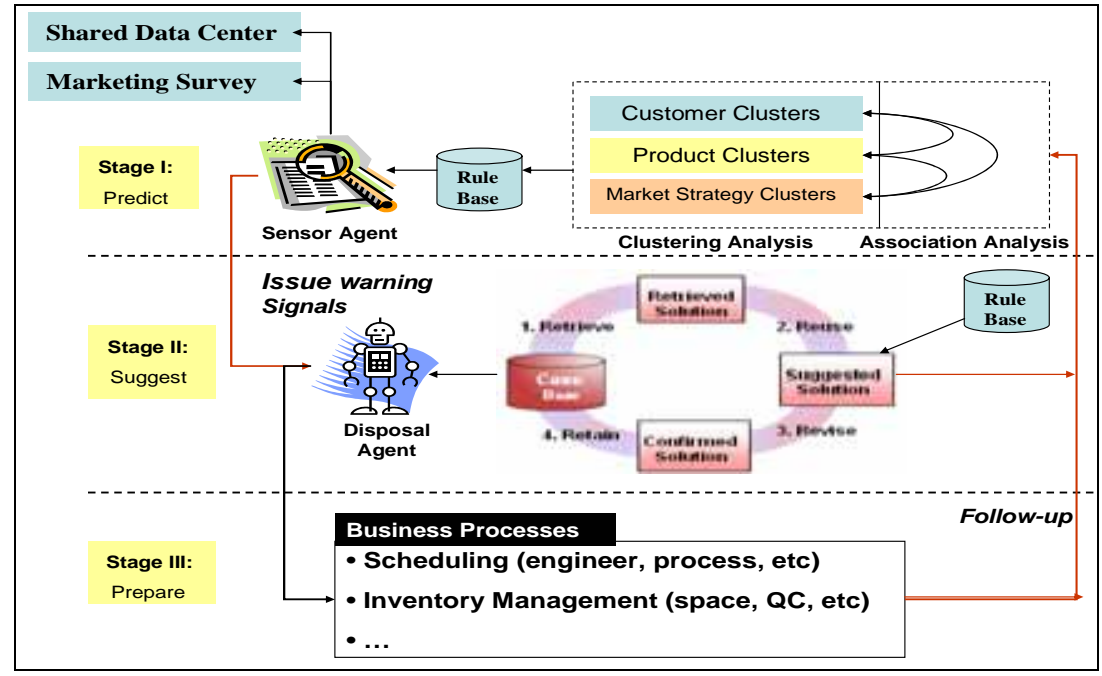

Fig. 4. The cooperation between sensor agent and disposal agent

\subsection{The Integrated System Framework}

As illustrated in Fig. 4, the framework has three stages. At stage I, the sensor agent monitors the data; predicts the possibilities of reverse activities, and transmits different warning signals to the disposal agent. The rule base comes from heuristics, and is periodically updated by data mining techniques (e.g., clustering and association analyses). At stage II, the disposal agent recommends feasible treatments from past cases and referencing rules. At stage III, for possible serious effects, disposal might further recommend or automatically initiate some related business process preparations (e.g., scheduling). Additionally, the disposal agent should notify the sensor agent of its treatment, and ask for a necessary follow-up. For instance, if a sensor agent discovers that the frequencies of customer complaint phones have risen, and predicts that the possible return rate is likely to increase, then the disposal agent recommends employing customer specialists to listen to customer concerns. After the treatment has been completed, the sensor agent performs a customer satisfaction survey to check whether the problems have been solved. The sensor agent also gives the disposal agent the evaluation feedback concerning the effectiveness of the treatment. Based on the feedback, the disposal agent adds annotations to the original case base, and recommends further treatment if needed. 


\section{Illustrative Scenarios}

To understand the proposed framework clearly, the three classes of reverse logistic activity are described as follows.

\subsection{Return Scenario}

According to the proposed framework, the sensor agent monitors the data, which are gathered from the consumer site and shared data center; performs weekly crossanalyses to diagnose the return probability, and transmits alarm signals. For instance, assume customer is making an increasing number of complaints, and that her (his) profile (Gender, Education) $=($ Female, High) matches one return pattern in Table 3. The sensor agent verifies the warrant period of the related transaction. If the guarantee period has expired, then a "moderate" signal is sent. Conversely, if the product is still under guarantee, then an "influential" signal is sent, while if the original transaction amount was also large, then a "serious" signal is flagged. The disposal agent then recommends appropriate treatments. For moderate signals, the disposal agent automatically sends an e-mail to a customer acknowledging the customer's concerns. For "influential" signals, the disposal agent advises a customer specialist to contact the customer in order to prevent possible return. For serious signals, the disposal agent recommends performing related business processes such as preparing return stock-location. After the treatment is completed, the sensor agent should follow up the customer satisfaction and give feedback to the disposal agent. The proposed framework could provide an early warning to the manufacturer about possible returns, and additionally could summarize the top 10 return reasons for product re-design. The ITD would increase under this framework.

\subsection{Repair Scenario}

Based on the proposed framework, the sensor agent would analyze the complaints from consumers monthly, and calculate the repair possibilities. For instance, suppose that some customers of electronic products live in the moist area, matching a rule in Table 2. The sensor agent judges, according to the past data, that some parts of these products might malfunction later. If these parts are normal materials, then a "moderate" signal is transmitted. If these parts contain special materials, then an "influential" signal is sent. If the repairing behaviors would require particular engineer skills, then a "serious" signal is flagged. The disposal agent recommends appropriate treatments to the decision maker. For a "moderate" signal, the disposal agent verifies the material stocks, and automatically schedules these repair requirements. For "influential" signals, the disposal agent recommends material procurements to the decision maker. In this case, owing to the longer repair period, the disposal agent arranges a temporary replacement product for customers. For serious signals, the disposal agent schedules another engineer, or recommends further training for engineers. After the treatment is completed for certain period (say one month), the sensor agent follows up customer opinions, and gives feedback to the 
disposal agent for further improvement. The ITD of the SCM is higher under the proposed framework than in other systems, enabling the repair center to prepare for possible repairs to accelerate the repair time.

\subsection{Recycling Scenario}

According to the proposed framework, database triggers notify the sensor agent the possibilities for recycling when the product approaches the end its life. The product size and materials is checked. If the product materials are normal, then the sensor agent sends a moderate signal. If the products contain toxic or harmful materials, then the senor agent sends a "serious" signal. The disposal agent then recommends treatments to the decision maker. For a "moderate" signal, distributors are recommended to conduct relationship marketing to their customers to express concerns about their product usage. Additionally, some notification messages could be transmitted automatically to the recycling collector to raise the ratio of recycled material. For serious signals, the disposal agent should report to the decision maker to comply with WEEE and RoHS requirements. The proposed framework raises the ITD of SCM. Moreover, the recycling ratio could be expected to increase if the recycling promotion becomes more active.

\section{Conclusions}

Reverse logistic activities have recently become a critical issue for both consumer and producer sites, but present some dilemmas. (1) Businesses are increasingly adopting loose return policy as strategy. However, in practice, the returned products are stocked by distributors, cannot be processed quickly by manufacturers to regain economic value quickly. (2) As new environmental laws are increasingly being enforced, recycling activities are additional burdens to the manufacturer, but are also social and environment responsibilities. Additionally, the recycling behaviors are not necessary for customer, for whom the reward is limited. Therefore, recycling is difficult to implement well in practice. (3) Repair is inconvenient for both customers and repair centers. Customers cannot use their products during the repair period. Thus, decreasing the repair time could improve customer's satisfaction. However, without proper information, repair centers cannot schedule the required resources to shorten the repair time.

This study presents an agent-based framework to improve information transparency degree of these reverse activities. A sensor agent operates like an early warning system to detect possible reverse activities actively. A disposal agent operates like a consultant, recommending treatments to decision maker, and even arouse related business processes automatically. The proposed framework is expected to increase the supply chain's information transparency degree, and improve the performance of reverse supply chain activities. Future research will concentrate on implementing this framework, and on verifying its performance and effectiveness using real-world data and field studies. 


\section{References}

1. 1. Aamodt, A., and Plaza. E.: Case Based Reasoning: Foundational Issues, Methodological Variations, and System, Approaches, AI Communications. IOS Press. 7(1) (1994) 39-59

2. Beamon, B.M.: Designing the Green Supply Chain. Logistics Information Management. 12(4) (1999) 332-342

3. Campbell, G.C.: Merchandise Returns: Retailer's Viewpoint. Quarterly Review of Commerce. 8(2) (1941) 141-151

4. Carter, C.R.: Purchasing and Social Responsibility: A Replication and Extension. Journal of Supply Chain Management. 40(4) (2004) 4-16

5. Emerson, D., and Piramuthu, S.: Agent Based Framework for Dynamic Supply Chain Configuration. Procedings of the $37^{\text {th }}$ Hawaii International Conference on System Sciences, (2004) 1-9

6. Guide, D.R., Jayaraman, V., Srivastava, R., and Beton, W.C.: Supply Chain Management for Recoverable Manufacturing Systems. Interface. 30(3) (2002) 125-142

7. Inderfurth, K.: Impact of Uncertainties on Recovery Behavior in a Remanufacturing Environment. International Journal of Physical Distribution \& Logistics Management. 35(5) (2005) 318-336

8. Kempfer, L.M.: New Ideas for Handling Electronic Product Returns. Material Handling Management. 60(5) (2005) 35-36

9. Klausner, M. and Hendrickson, C.T., "Reverse Logistics Strategy for Product Take Back," Interfaces. 30(3) 2000, 156-165

10. Kulshreshtha, P., and Sarangi, S.: No Return, No Refund: An Analysis of Deposit Refund Systems. Journal of Economic Behavior \& Organization. 46 (2001) 379-394

11. Lambert, A.J.D., Boelaarts, H.M., and Splinter, M.A.M.: Optimal Recycling System Design: With an Application to Sophisticated Packaging Tools. Environmental and Resource Economics. 28(3) (2004) 273-299

12. Min, H., Ko, H.J., and Ko, C.S.: A Genetic Algorithm Approach to Developing the MultiEchelon Reverse Logistics Network for Product Returns. Omega. 34 (2006) 56-69

13. Mollenkopf, D.A.: The Hidden Value in Reverse Logistics. Supply Chain Management Review. 9(5) (2005) 34-43

14. Papazoglou, M.P.: Agent-Oriented Technology in Support of E-Business. Communications of the ACM. 44(4) (2001) 71-77

15. Richey, R.G., Chen, H., Genchev, S.E., and Daugherty, P.J.: Developing Effective Reverse Logistics Programs. Industrial Marketing Management. 34 (2005) 830-840

16. Rogers, D.S., and Tibben-Lembke R.S.: An Examination of Reverse Logistics Practices. Journal of Business Logistics. 22(2) (2001) 129-148

17. Tibben-Lembke R.S., and Rogers, D.S.: Differences Between Forward and Reverse Logistics in a Retail Environment. Supply Chain Management. 7(5) (2002) 271-282

18. Walton, S.V., Handfield, R.B., and Melnyk, S.A.: The Green Supply Chain: Integrating Suppliers into Environmental Management Processes. International Journal of Purchasing and Materials Management. 34(2) (1998) 2-11 